\title{
Las revistas: ¿Fin de un proyecto?
}

\author{
Journals: the ending of a project? \\ Pablo Hugo Rocca Pesce \\ Universidad de la República - Montevideo, Uruguay
}

Resumen: Después de servir como conducto principal para la trasmisión del pensamiento y para la circulación de los textos literarios durante toda la edad moderna, las revistas están amenazadas por el imperio de Internet. Este artículo revisa algunos momentos en que la producción textual, los autores, los bienes culturales y los lectores se traman desde el periodismo y la revista cultural (sobre todo literaria), a partir de varios ejemplos latinoamericanos, para concluir en algunas propuestas sobre las actuales posibilidades.

Palavras-chave: Periódicos; América Latina; Internet

\begin{abstract}
After having served as the main conduct for the transmission of thought and the circulation of literary texts during all the modern age, magazines are being threatened by the Internet empire. This article checks some moments in which text production, authors, cultural assets and readers are built up from journalism and the cultural (mostly literary) magazine, out of several Latin American examples, so as to make some propositions concerning the possibilities of the present.
\end{abstract}

Keywords: Journals; Latin America; Internet

\section{Viajes}

En 1938 un ya promisorio Jorge Amado visitó Montevideo. En una ciudad donde la "industria del libro no se ha desarrollado", el visitante se asombró de que las muchas librerías céntricas rebosaran de "todo lo que se publica en España, en Argentina y en Chile. Miles de ediciones que atestan las vidrieras. Revistas y más revistas, principalmente argentinas". ${ }^{1}$ Hirieron los ojos de este pasajero varios tipos de publicaciones periódicas y no sólo las culturales o, para decirlo con la nomenclatura de la época, las revistas literarias, ya que después de todo en la mayoría privaba ese discurso.

\footnotetext{
1 "Considerações sem poesia feitas da janela do Dante Hotel” se publicó, como parte de una serie de pequeñas notas referidas a Uruguay -insertas en un proyecto mayor de apuntes de viaje por América-, en el periódico Dom Casmurro, Rio de Janeiro, 7 de abril de 1938. Junto a otros momentos del viaje el texto fue recogido en el libro $A$ rondas das Américas, Jorge Amado. Salvador, Fundação Casa de Jorge Amado, 2001. (Estabelecimento de texto, introdução e notas por Raúl Antelo), p.66-68. En La Diaria, Montevideo, 30 de setiembre de 2016, en traducción y nota introductoria de mi autoría.

Una primera versión de este texto fue leída en conferencia de cierre en el Seminario sobre revistas organizado por el grupo de investigación sobre revistas dirigido por los doctores Daniel Badenes y Karina Vázquez en la Universidad de Quilmes, Argentina, en diciembre de 2016, a quienes
}

Seis años después, la poeta Cecília Meireles se subió a un tren en Rio de Janeiro con rumbo sur. Llegó a Montevideo, anduvo, conoció personalmente a varios de los cuales ya conocía por carta, por libros y, sobre todo, porque los había leído en revistas. Después cruzó en barco a Buenos Aires, una ciudad que ansiaba recorrer quizá porque ya tenía muy presente su vida literaria gracias a "la revista Sur, que es una norma para toda América", en la que se "selecciona y congrega de tal modo que representa un criterio literario de primer orden". ${ }^{2}$ Revistas de todas clases y para todas las clases sociales marcaban el diapasón de la cultura rioplatense hacia 1940. Su ritmo seguirá creciendo y ramificándose por las páginas de la

\footnotetext{
agradezco la posibilidad de volver sobre el tema. Con estas notas continúo otras reflexiones, sobre todo la ya lejana y extensa titulada "Por qué, para qué una revista (Sobre su naturaleza y su función en el campo cultural latinoamericano)", en Hispamérica, Maryland, University of Maryland, año XXXIII, n. 99, p. 3-19, diciembre 2004. Y la más cercana que se titula "Sobre una estética iridiscente (De las revistas hispanoamericanas en los sesentas)", en Annais do XI Seminário de História da Literatura, Maria Eunice Moreira (org.), Porto Alegre, Ed. PUCRS, $2016<\mathrm{http}$ ://ebooks pucrs.br/edipucrs/anais/sihl/>.

2 "Buenos Aires no inverno", en Crônicas de viagem, 1, Cecília Meireles. São Paulo, Nova Fronteira, 1998. Originalmente en A Manhã, Rio de Janeiro, 1으 de noviembre de 1944. La traducción de la cita me corresponde.
} 
prensa diaria, semilla de su existencia más segura en el siglo XIX.

Hubo que sortear muchos obstáculos para que se llegara a esta explosión de oferta bibliográfica donde no había industria editorial, según la atinada y pragmática observación de Jorge Amado, o para que donde la había, en Buenos Aires, se afirmara una potente herramienta minoritaria como Sur, que en 1944 tenía trece años de existencia y gravitación, la cual ya ultrapasaba el orbe de lengua española. Como sea, la búsqueda de respuestas para construir revistas venía de antaño, y con esas experiencias se había logrado cimentar algunas posibilidades que encontrarán un notable desarrollo al amparo de los dispositivos de la letra y sus prestigios.

Dos ejemplos tomados de momentos cruciales en las dos márgenes del Plata nos permiten cumplir un recorrido que siguen interpelando nuestro presente. El primero viene de la tormentosa época de la formación republicana, antes y después de la caída de Juan Manuel de Rosas, antes y después de la llamada Guerra Grande. Segundo, me detendré rápidamente en los primeros años del siglo XIX a través de algunas ideas de Rubén Darío y otras de José Enrique Rodó sobre periodismo y literatura. Luego, entre apresurado y anacrónico, daré el salto de garrocha de un siglo y haré algunas muy modestas proposiciones sobre la revista como forma y sobre sus lectores como su fuerza motriz.

\section{Primer momento: pensar una presencia}

En un informe sobre educación de 1853, Sarmiento hizo el deslinde entre la biblioteca americana y las novelas, que vienen de allende el mar:

\begin{abstract}
Las imprentas americanas no producen otro libro para la general lectura [que las novelas], porque es el único que encuentra lectores y compradores.

¿Hay otros libros que el Don Quijote o el Gil Blás de Santillana, que estén en cierta proporción generalizados en América? Nosotros no conocemos sino El Judio Errante y los Misterios de París; pero en uno y otro caso no vemos sino el hecho material de las numerosas ediciones que de ellos se han hecho en español, por donde se ha logrado que una buena porción de ejemplares se difunda en la sociedad. ${ }^{3}$
\end{abstract}

Sarmiento ve el problema con claridad: los debilísimos estados platenses podían hacer muy poco para ofrecer otro tipo de literatura, ni siquiera podían acompasar la producción de novelas vernáculas a las

\footnotetext{
3 "Bibliotecas locales", en Ortografia, instrucción pública, 1841-1854. Buenos Aires, Ed. Luz del Día, 1949. (Tomo IV de Obras completas de D.F.S.). [Monitor de las escuelas primarias, Buenos Aires, 15/VII/1853], p. $449-450$.
}

extranjeras, mal o bien traducidas. Periódicos y revistas, con o sin aliento pedagógico, con o sin apoyo oficial, fueron las únicas salidas para ampliar el campo de lectores que, de a poco, se incorporaban a la alfabetización. Desde estos medios, precarios o elegantes, se fundó una cultura letrada en América Latina. Por eso la contaminación de los discursos prosperó en estas entidades misceláneas. Para que triunfara lo que podría llamarse una voluntad de especificidad en la revista habrá que esperar hasta el Novecientos fuera de algunos casos aislados, como $\mathrm{El}$ Iniciador o, mucho más tarde, la Revista del Plata.

En 1851, el mismo año en que concluyó la larga Guerra en la margen oriental del Plata, y a poco de la caída de Rosas, ignorante de una y otra circunstancias sudamericanas, Schopenhauer publicó unas notas en las que una vez y otra también se crispa ante el aluvión de papeles impresos. Lo irrita la multiplicación de libros, sobre todo de novelas de aventuras, cuyo nombre ni siquiera se atreve a mentar, porque devoran el tiempo de los lectores, abaratan el gusto y atentan contra el pensamiento auténtico, que interroga el universo y con esa operación devuelve al individuo un sentido a su vida. Para todos estos males queda un recurso moderno posible de inmediata resistencia. Dice Schopenhauer:

las revistas literarias deberían oponer una especie de dique fustigando sin piedad, mediante juicios íntegros, justos y severos, toda producción de un escritor sin talento $[\ldots]$ ¿Existe o ha existido nunca entre ellas una revista que pueda jactarse de no haber hecho nunca el elogio del garabateo más nulo, de no haber criticado o denigrado nunca una obra excelente, o bien de no haberla tratado con ironía, como una cosa insignificante, a fin de apartar de ella las miradas? ¿Una revista que haya seleccionado siempre a conciencia los libros que presenta, teniendo en cuenta su importancia y no la recomendación de algún compadre, las consideraciones gremiales, o incluso las gratificaciones de los editores? ${ }^{4}$

El filósofo alemán cree que la revista se está transformando en conducto privilegiado para la trasmisión del veneno que corrompe la sensibilidad ya no de quienes tienen que construir una nación fuerte, nueva y republicana, como querían los civilizadores americanos de la primera hora, sino de la propia naturaleza del sujeto. La ficción desplazaba a la filosofía y a la poesía. Pronto, y esto Schopenhauer lo intuye, la revista impulsaría el fait divers, la crónica liviana, el reino de la información antes que el de la reflexión. Así fue, en gran medida. El siglo XIX, explica Alain Vaillant, "se vuelve prioritariamente narrativo [y de ahí que] la progresión de la novela debe

\footnotetext{
4 Fragmento 281, en Sobre los libros, el lenguaje y la escritura, Arthur Schopenhauer. Capellades, José J. de Olañeta, 2015. (Trad. de Edmundo González Blanco y Esteve Serra), p. 130-131.
} 
correlacionarse probablemente con el ascenso del modo narrativo periodístico", ya que la "periodicidad es el corazón viviente de la literatura" de esa centuria. ${ }^{5}$

En esa lucha de discursos empiezan a odiarse dos modelos de revistas. Esos modelos, el de las generalidades y el de la especialización, ya están definidos en Europa. Pero en América Latina el antagonismo se deslíe. A veces se traduce en una red intrincada y hasta indisociable en la que conviven fuerzas opuestas: las que pugnan por la novelización de la vida con las que promueven el espacio de la reflexión y la afirmación de la poesía antes que todas las cosas. En términos concretos: Caras y Caretas se opone a la Revista de América pero, en varios puntos, pueden coincidir, pueden publicar a los mismos autores aunque, a veces, publiquen textos de géneros o de extensión diferentes. La diferencia es, también, de carácter material en el sentido más lato del término. Cuando en Europa hay una tradición varias veces centenaria de edición de libros en América casi no han existido cuando, de pronto, las revistas del tipo que fuere aparecen como solución práctica a esta carencia y como canal comunicativo entre las minorías y, a veces, con las mayorías.

Como sabemos, en el Novecientos las minorías hacen el esfuerzo desesperado por construir un espacio estético que, ya lo han demostrado Rafael Gutiérrez Girardot o Julio Ramos, no es un huerto incontaminado de política. Dicho de otra manera, hacia 1900 el antagonismo entre escritor y periodista, contra lo que proponen los esquemas didácticos o los presurosos lugares comunes, a veces se disuelve y aun puede engendrar otra dicotomía: la revista de "arte" y el periódico. Pero aun así, tal regla no siempre se cumple.

\section{Segundo momento: construir una sensibilidad}

En 1902 el entonces ubicuo Manuel Ugarte reunió en libro una serie de crónicas sobre la vida cultural parisina. Rubén Darío escribió para ese libro un riquísimo prólogo en el que, entre otras ideas, se alzó contra el descrédito del periodista en defensa de esta actividad siempre que llevara consigo una escritura elegante y una vocación universal: “¿Por qué -se pregunta-, sin tener necesidad, [Ugarte] ha preferido al laborar reposado del libro, $[. .$.$] la$ tarea periodística, el oficio de cronista, duro y dificultoso [...]?"Y agrega, de inmediato, que sabe "bien que entre los intelectuales la palabra periodista tiene una significación inferior". Como muestra de su aprecio reivindica para sí, por mediación de un juicio de Gómez Carrillo, que ante todo él mismo es periodista. Ser escritor en lengua

\footnotetext{
5 Vaillant, Alain. "Poética de la escritura periódica: cuestiones de método y de historia literaria". Secuencia. Revista de Historia y Ciencias Sociales [en línea], n. 62 (2005a), p. 195-206. Acceso en octubre de 2016: <http:// www.redalyc.org/articulo.oa?id=319136829009>.
}

española se le aparece como una tarea demasiado ingrata porque "Muy pocos leen. La hoja diaria parece bastar para satisfacer las curiosidades de la mayoría. Y es inútil decir que los diarios, por excelentes que sean, no alcanzan a consolidar una opinión filosófica". ${ }^{6}$ En otras palabras, Darío ensaya una versión más moderada de las ideas de Schopenhauer matizadas con un conocimiento empírico de las dificultades de España y de América por parejo. Porque sabe que hasta que no haya públicos preparados no habrá revistas verdaderas, sabe que sin esos lectores no existirá movimiento bibliográfico creíble. El propio libro que auspicia con su prólogo no sale en Buenos Aires ni en México sino en París, en la casa Garnier, una de las pocas que tiene la capacidad de distribuir sus ediciones en toda la geografía de lengua española, y aun en Brasil.

El 14 de abril de 1909 se inaugura en Montevideo el "Círculo de la prensa", que tiene su sede provisoria en el entonces floreciente Ateneo de Montevideo, que ahora y desde hace muchos años (demasiados años) yace abandonado frente a la Plaza Libertad, en el centro de la capital uruguaya. Rodó es convocado como orador principal para el acto y en su largo discurso va más lejos que Darío:

Ser escritor y no haber sido, ni aun accidentalmente, periodista, en tierra tal como la nuestra, significaría, más que un título de superioridad o selección, una patente de egoísmo. Significaría no haber sentido nunca repercutir dentro del alma esa voz imperiosa con que la conciencia popular llama a los que tienen una pluma en la mano, a la defensa de los intereses comunes y de los comunes derechos, en las horas de conmoción o de zozobra [...].

Y a este diagnóstico sobre la responsabilidad civil, que se alía a la ética, asigna al periodista un papel entre decisivo y secundario a la vez:

Las peculiares condiciones de una cultura naciente y apenas diferenciada en funciones de especial aplicación, han hecho que el carácter de nuestra intelectualidad se personifique hasta hoy en el periodista: especie de improvisador enciclopédico, dispuesto, como el teólogo de los tiempos pasados, a enterarse y juzgar de todas las cosas. Nuestros novelistas, nuestros dramaturgos, nuestros líricos, todos, con rarísima excepción, han sido alguna vez periodistas $[\ldots]$ del periodismo adquirieron esa disciplina del trabajo, ese hábito de la producción ágil y asidua, y esa gimnasia de claridad y precisión, que desentumecen el estilo y adiestran las energías del entendimiento [...].

\footnotetext{
6 "Prólogo", Rubén Darío. Crónicas del bulevar, Manuel Ugarte. Paris, Garnier Hermanos, Libreros Editores, 1903: V. Cit. por <https://archive $\mathrm{org} /$ stream/crnicasdelbulev00dargoog\#page/n $5 /$ mode/1 up $>$ (Consultado el $28 / 11 / 2016)$
} 
Para concluir en su disertación que el "escritor es, genéricamente, un obrero; y el periodista es el obrero de todos los días: es el jornalero del pensamiento". ${ }^{7}$ Como si dijera: la publicación periódica, única alternativa real para una sociedad débilmente letrada y pobre es al libro lo que el periodista al escritor. Nadie, hasta donde tengo noticia -ni siquiera Darío-, fue entonces capaz de analizar el fenómeno con tanta lucidez.

\section{Lectores ayer, ¿lectores hoy?}

La revista empezó, así, a multiplicar sus facetas. Supuso una fuga del canon o pudo afirmarlo. Si logra alguna forma de éxito reproductivo, en la historia cultural o literaria o en el rubro que sea, pasará airosa la prueba de la lucha contra el tiempo, tal vez ingresará al panteón o se convertirá en monumento una vez que se apague cualquier rumor de la expresión de la vida y sus entredichos. Antes, la revista es acto en el tiempo. Algunas lo interpelan, otras no pasan de la simple reunión de piezas inarticuladas o inoperantes y viven -poco o mucho- tal vez con la expectativa de volverse objeto de estudio de especialistas futuros. Es decir que pasan sin cumplir su objetivo fundamental: el de hacer pie en el presente. Esclava de la periodicidad, la revista vence si alcanza lo que llamaría una actividad iridiscente. Una revista iridiscente multiplica los efectos posibles de sus distintos matices y colores cuando esa experiencia colectiva consigue amalgamar un grupo que, aun situándose en el centro del remolino de las tensiones entre arte y política, toma distancia del discurso monológico. ${ }^{8}$

Cada medio, sabemos, busca su receptor, lo crea o incluso lo moldea a su necesidad, como lo pueden ejemplificar, para citar ejemplos, los casos de Marcha de Montevideo sobre todo entre 1950 y 1974 o de Crisis, de Buenos Aires hacia 1970. Más que de cualquier otra modalidad de escritura envasada en la forma que fuere, la dependencia de la revista con el público es crucial. A sus lectores debe las posibilidades básicas de vida, material y simbólica. Podrían identificarse tres tipos de lectores de revistas:

1. el lector próximo o contemporáneo, para el que hipotéticamente se destina el texto o la ilustración que interviene, en mayor o menor escala, en el diálogo y la actitud crítica que impone lo inmediato o lo soslaya. La polémica es la derivación expresiva y la mejor manifestación

\footnotetext{
7 "La prensa de Montevideo. Discurso pronunciado en el acto de la inauguración del 'Círculo de la prensa' de Montevideo, el 14 de abril de 1909”, en El mirador de Próspero, 1913. Cit. por edición de Clásicos Uruguayos, Biblioteca Artigas, tomo II, 1965, p. 140.

8 Para un pequeño desarrollo de esta idea véase el mencionado "Sobre una estética iridiscente (De las revistas hispanoamericanas en los sesentas)"/ $<$ http://ebooks.pucrs.br/edipucrs/anais/sihl/>.
}

pública sostenida de este tipo de recepción que, a la larga, impone paradigmas.

2. el lector futuro, al que la revista, a sabiendas o no, está atenta. Se trata de un receptor abstracto, de algún modo prefigurado por otras operaciones del lector anterior en los debates, que a su vez parece recortado por las intervenciones de historiadores y críticos.

3. el lector imaginado por el texto, en particular por los discursos argumentativos; un receptor que está más adentro de la propia naturaleza de lo escrito, un lector implícito y cómplice capaz de compartir algunos signos o descodificar algunos gestos que, pronto, el tiempo se lleva a veces sin que tengamos mayores posibilidades de recuperarlos.

Si el periódico del siglo XIX trató de encerrar el tiempo en sus corrales, el investigador se encuentra con una primera dificultad: definir las secciones periodísticas, verlas actuar como un conjunto dinámico cuando se alcanza este propósito. Algunas secciones, como dice Vaillant, se definen a sí mismas: el editorial, el folletín, la crónica, la gacetilla, la crítica, el reportaje, la entrevista. Otras son mucho más lábiles, movibles, efímeras. Esta fuerte matriz plantada hacia 1850 que se fue filtrando en el siglo XX ha estallado con Internet. Es cada día más evidente que se retira con pies ligerísimos a medida que el papel se extingue como medio; es cada vez más ostensible que están surgiendo otras posibilidades para la nueva revolución de la lectura y que tal transformación nos obliga a reconsiderar las formas. Dicho en otros términos, definir una revista no sólo porque tras de sí se agazapa o se hace visible un grupo (pequeño o grande, heterogéneo u homogéneo); no sólo porque responde a una periodicidad (regular o algo azarosa, de vida larga o de vida breve); no sólo porque se enfrenta al sistema o forma parte de él o porque, al fin, pone énfasis en cierto campo de trabajo. Una revista podrá tener alguna esperanza de vida en las condiciones actuales que no parecen auspiciosas si adopta una política, es decir si cumple con una visión del mundo y de la escritura que, con o sin recursos, horada así sea un pequeño espacio de la vida cultural. Y desde ese margen se extiende por otros medios. Los que sean.

En la era de la instantaneidad, de la aceleración y el crecimiento incontrolado de la información, en el tiempo sin tiempo de la ilusoria presencia de todos en las redes sociales, la revista como escaparate dinámico para la exposición de variedades está bajo amenaza. Y lo está no sólo porque el papel se retira de nuestro entorno sino porque leer una revista requiere cierto reposo para el diálogo, un reposo y una concentración de la que ya no disponemos.

"Las revistas, fin de un proyecto", fue el primer título que pensé para este texto. Pensé, luego, que era 
demasiado apocalíptico, tal vez injusto, y por eso incorporé los signos de interrogación. De los restos de un pasado en el que hoy pocos reparan hablan los diccionarios, las enciclopedias, los mapas, los almanaques, los diarios, los libros populares: gran parte de los artefactos que hicieron la modernidad y que, hoy, están gravemente heridos, por no decir extintos en cuanto impresos. ¿Por qué tendría que salvarse la revista, tal cual la conocimos a lo largo de casi dos siglos, en medio de cambios tan radicales? ¿Cómo podrá preservar su fuerza y su capacidad de provocación que acude al fragmento y lo trasciende?

Si un visitante inadvertido pasa por Montevideo, hoy, a diferencia de lo que le pasó a Jorge Amado en 1938, no se encontrará con "revistas y más revistas", ni podrá decir -como dijo con razón Cecilia Meireles por ese tiempo-que en Buenos Aires una revista fija la norma de la escritura en español. Los que tienen ya varios años observarán, no sin melancolía, la acelerada reducción y hasta extinción de los quioscos, antes rebosantes de todo tipo de publicaciones periódicas en las avenidas centrales de Buenos Aires y Montevideo y hasta en los barrios. Esos que impresionaron a Jorge Amado. Las redes sociales más que las revistas parecen ser las respuestas contemporáneas, salvo en la formulación académica en que estas reuniones de estudios siguen convocando más la voluntad profesional que la energía expresiva de la literatura. En esas redes habitará lo diverso más que lo uno, allí se convertirá la sociabilidad de los pocos de antaño, en las redacciones de los diarios o en las tertulias de los grupos, en una multitud sin cara y hasta, a veces, con nombre falso. Fin de un proyecto y comienzo de otro, entonces.

\section{Referencias}

DARIO, Ruben. "Prólogo". Crónicas del bulevar, Manuel Ugarte. Paris: Garnier Hermanos, Libreros Editores, 1903: V. Cit. por <https://archive.org/stream/crnicasdelbulev00 dargoog\#page/n5/mode/1up> (Consultado el 28/11/2016).

MEIRELES, Cecilia. Buenos Aires no inverno. En: Crônicas de viagem. São Paulo: Nova Fronteira, 1998.

SCHOPENHAUER, A. Fragmento 281, en Sobre los libros, el lenguaje y la escritura, Arthur Capellades, José J. de Olañeta, 2015. (Trad. de Edmundo González Blanco y Esteve Serra). p. 130-131.

VAILLANT, Alain. Poética de la escritura periódica: cuestiones de método y de historia literaria. Secuencia. Revista de Historia y Ciencias Sociales [en línea], n. 62, p. 195-206, 2005a. Acceso en octubre de 2016: <http://www.redalyc.org/articulo. oa? $\mathrm{id}=319136829009>$.

Recebido: 20 de abril de 2017

Aprovado: 25 de junho de 2017

Contato:

Pablo Hugo Rocca Pesce < pabloroccapesce@gmail.com> 